\title{
DO CORDÃO AO CORDEL: REFLEXÕES SOBRE O TRABALHO COM PROJETO INTERDISCIPLINAR NA EDUCAÇÃO BÁSICA
}

\author{
Gislene dos SantosSala ${ }^{1}$ \\ Ricardo Luiz de Bittencourt ${ }^{2}$ \\ AlessandraSavi ${ }^{3}$ \\ JéssicaPazJacinto ${ }^{4}$ \\ Larissa Rodrigues Figueiredo ${ }^{5}$
}

\begin{abstract}
RESUMO
Este trabalho relata a experiência realizada pelos bolsistas do Programa de Iniciação à Docência (PIBID), subprojeto Interdisciplinar, da Universidade do Extremo Sul Catarinense - UNESC em uma escola pública municipal de Criciúma/SC através do projeto intitulado "Do Cordão ao Cordel".O referencial teórico é dividido em dois segmentos, apresentando primeiramente sobre a origem da literatura em cordel, suas possibilidades na educação e na formação de professores e, em seguida, a respeito das leituras interdisciplinares desenvolvidas por este projeto. Além de ampliar o repertório cultural da comunidade escolar, fortalecer a leitura, contextualização e problematização através de um trabalho com vistas à interdisciplinaridade, o projeto também contribuiu com a formação dos pibidianos para o exercício da docência.
\end{abstract}

Palavras-chave: Formação de professores, Literatura em cordel, Interdisciplinaridade.

\section{THE CORD TO CORDEL : REFLECTIONS ON THE WORK WITH INTERDISCIPLINARY PROJECT IN BASIC EDUCATION}

IUNESC; Rua João Batista Rita, n 16, Bairro Santa Luzia, Criciúma-SC, CEP: 88807213; gislene_salla@unesc.net.

2UNESC; Rua da República 80/302, Bairro Comerciário, Criciúma-SC, CEP: 88802420; rlb@unesc.net.

3UNESC; Rua Visconde de Cairu 47/309; Bairro Santa Bárbara, Criciúma - SC; alesavi33@gmail.com

4UNESC; Rua Abílio Paulo, 270/403, Centro, Criciúma-SC, CEP 88802060; jessicapaz@unesc.net;

5UNESC; Rua Projetada, 2. Bairro Cristo Rei. Içara-SC. 88820000; laraahw_@hotmail.com.

Criar Educação, Criciúma, v. 6, n², julho/novembro 2017.- PPGE UNESC 


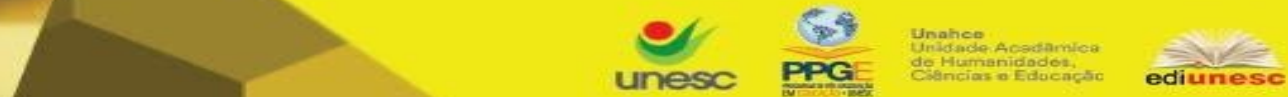

\section{ABSTRACT}

Este trabalho relata a experiência realizada pelos bolsistas do Programa de Iniciação à Docência (PIBID), subprojeto Interdisciplinar, da Universidade do Extremo Sul Catarinense - UNESC em uma escola pública municipal de Criciúma/SC através do projeto intitulado "Do Cordão ao Cordel". O referencial teórico é dividido em dois segmentos, apresentando primeiramente sobre a origem da literatura em cordel, suas possibilidades na educação e na formação de professores e, em seguida, a respeito das leituras interdisciplinares desenvolvidas por este projeto. Além de ampliar o repertório cultural da comunidade escolar, fortalecer a leitura, contextualização e problematização através de um trabalho com vistas à interdisciplinaridade, o projeto também contribuiu com a formação dos pibidianos para o exercício da docência.

Keywords: Teacher training, Literature line, interdisciplinarity.

\section{Introdução}

Este artigo apresenta reflexões sobre a contribuição de projetos interdisciplinares para a construção de um conhecimento significativo e integral, fortalecendo a leitura, a contextualização e a problematização.

Assim, o trabalho relata a experiência realizada pelos bolsistas do Programa de Iniciação à Docência (PIBID), subprojeto Interdisciplinar da Universidade do Extremo Sul Catarinense - UNESC, em uma escola pública municipal de Criciúma/SC.

Neste sentido, tratando-se da estrutura do artigo, o mesmo é dividido em dois segmentos. No Primeiro apresentamos reflexões a respeito do cordel, como ferramenta metodológica e manifestação artístico-cultural e, assim, qualificar a construção do conhecimento. Também destacamos esse gênero textual e literário como possibilidade de contribuir para a formação docente. No segundo segmento relatamos como as ações do projeto foram desenvolvidas de modo que a interdisciplinaridade se efetivasse em nossas práticas.

Trabalhar de maneira interdisciplinar, quebrando as barreiras curriculares escolares, é um desafio a ser enfrentado na escola. Desta forma, o projeto desenvolvido, além de ampliar o repertório cultural da comunidade escolar a partir da literatura de cordel, visou trabalhar a temática com vistas à interdisciplinaridade, envolvendo diferentes componentes curriculares. Além disso, a experiência foi importante para qualificar a formação dos pibidianos 
para o exercício da docência e complementar a formação do professor que está atuando em sala de aula.

\section{De onde veio o cordel? Possibilidades na educação e na formação de professores.}

Falar de ensino de qualidade é um dos grandes desafios enfrentados pela Educação Básica, visto que, com ela caminham muitos fatores que necessitam de um olhar mais minucioso. Deste modo, podemos destacar anecessidade de melhores estruturas físicas para receber os alunos,que as políticas educacionais sejam elaboradas em parceria com os professores a partir da articulação de movimentos para efetivá-las na prática,que a formação inicial e continuada dos professores seja uma bandeira assumida por aqueles que governam nosso país.

Diante dessas reflexões, destacamos nesse texto, um projetoque visa à qualificação da formação docente através do Programa de Iniciação à Docência - PIBID, gerenciado pela CAPES. Este programa tem como objetivo aproximar os acadêmicos de licenciatura das escolas de Educação Básica a fim de proporcionar experiências que dialoguem teoria e prática pedagógica no decorrer de sua formação. Nessa dinâmica, além de contribuir com a formação dos acadêmicos, o programa proporciona aos professores, que assumem a condição de supervisores, uma formação continuada em contexto. Formação esta que acontece através de leituras, pesquisas, reflexões sobre a prática e novas propostas para a sala de aula, em uma busca constante por aquilo que comentamos no início desse segmento, a qualidade da educação.

Neste caminho apresentamos nesse artigo uma experiência realizada pelos bolsistas do PIBID, subprojeto interdisciplinar, que é vinculado com a Universidade do Extremo Sul Catarinense - UNESC. Este subprojeto, além de aproximar os licenciados da realidade das escolas, tematiza as práticas de leitura em diferentes campos interdisciplinares. Assim, no projeto intitulado "Do Cordão ao Cordel" participaram acadêmicos dos cursos de

Criar Educação, Criciúma, v. 6, n², julho/novembro 2017.- PPGE UNESC 
Pedagogia e Letras em parceria com a professora supervisora formada em Artes Visuais.

Procurar metodologias diferenciadas que despertem a curiosidade dos alunos é uma das tarefas do professor e um dos desafios assumidos pelo subprojeto interdisciplinar. Para isso o planejamento e a pesquisa devem acompanhar o professor no decorrer de sua profissão, a fim de procurar novas alternativas, novas propostas, novas ideias, para sua prática pedagógica. Neste caminho, concordamos com Vasconcellos (2000) quando ele diz que a condição para que a construção do conhecimento aconteça é através de uma proposta de trabalho significativo, que valorize as particularidades dos alunos e contribua para a formação integral desses sujeitos em formação. Isso significa dizer, também, que a reflexão crítica deve ser uma constante no trabalho do professor, avaliando as ações a fim de qualificá-las e evitarmos, o que nos alerta Freire (2011), que sem a reflexão crítica sobre a relação entre teoria e prática pode transformar a teoria em blábláblá e a prática em pleno ativismo.

Neste caminho, após um longo período de observações sobre a prática e discussões teóricas a respeito da interdisciplinaridade, que o projeto "Do Cordão ao Cordel" foi construído. Nossas motivações vão ao encontro do que apresenta Gandin (2000) ao dizer que a questão central do planejamento escolar não pode ser engessada como os conteúdos, que são elencados previamente, serão transmitidos aos alunos. As aspirações do professor devem ser maiores que isso. Assim, nos preocupamos em construir um projeto que despertasse 0 interesse dos alunos, onde seus conhecimentos fossem valorizados e que thes proporcionasse novas experiências, construindo um conhecimento integrado.

Deste modo, ao construirmos esse projeto, podemos afirmar com segurança, que a formação dos professores envolvidos foi enriquecida, destacando que além dos bolsistas do programa, nesse projeto, os demais professores da escola aceitaram o desafio. Juntos, efetivamos um projeto que quebrou com as barreiras curriculares, contribuiu com a formação dos professores ao buscarem novas alternativas para sua prática e, principalmente, 
para a formação integral dos alunos através da construção de um conhecimento significativo.

O tema que norteou a tecedura do projeto foi relacionado ao cordel, referindo-se ao seu gênero textual e a literatura. O cordel são folhetos compostos com temas populares e que normalmente são expostos para venda pendurados em cordas ou cordéis. Esta forma de organização foi o que deu origem ao seu nome. Ademais, trata-se também da divulgação da arte, das tradições populares e dos autores locais. Sobre a origem do Cordel, Proença (1976, p. 23) relata que

\begin{abstract}
quanto a época de surgimento da literatura de cordel ou literatura popular em verso, não se encontrou a até hoje uma definição precisa, sabe-se apenas que foi assimilada em Portugal antes do século XVII como originária dos romances tradicionais que aqui chegaram também no século XVI e XVII, através de nossos colonizadores. Inicialmente, foram 'folhas soltas ou volantes' como, por exemplo, a história do Imperador Carlos Magno.
\end{abstract}

No Brasil a literatura de cordel, iniciou-se em meados do século XIX, se popularizando no Nordeste em mercados e feiras, sendo vendida pelos próprios autores. Também foi disseminada para outros estados, como Rio Janeiro e São Paulo nas feiras culturais, casas de cultura e livrarias.

Dentre os principais cordelistas brasileiros é importante citar Antonio Gonçalves da Silva conhecido como Patativa de Assaré. Ele foi uma das principais figuras da música nordestina e dos grandes nomes da literatura de Cordel do século XX. Segundo Ateu (2012), Patativa de Assaré iniciou a escrita de repentes por volta dos 12 anos, quando frequentava uma escola local, e se apresentava em festas e ocasiões importantes. Recebeu o pseudônimo de Patativa aos 20 anos de idade, por sua poesia ser comparada com o canto dessa ave.

ParaLessa (1973), a poesia popular divide-se em dois grandes gêneros: o "folheto" com oito páginas, e é o chamado caso de época, como por exemplo, o assunto do dia, o comentário político, a narrativa dos grandes desastres e calamidades, os crimes de sensação, a discussão temática do povo, fome, lamentações, etc. Já o "romance", possui dezesseis folhas ou mais

Criar Educação, Criciúma, v. 6, n², julho/novembro 2017.- PPGE - 
e, como o próprio nome indica, apresenta as histórias de amor ou de heroísmo, os temas épicos que mais falam ao povo.

As capas dos livretos em cordel são realizadas por um processo de gravação chamado de xilogravura, sendo que esta trata-sede uma manifestação popular. Segundo Maxado (1982), o significado epistemológico de Xilogravura, provém do grego: xylon(madeira) e grafhein(escrever), sendo um processo anterior a imprensa, um tipo móvel de madeira o qual era utilizado para impressão de imagens, letras e estampas em tecidos. Assim, utilizando pedaços de madeira como matriz, o artista gravador faz relevos em seus desenhos, para serem transferidos para o papel. Dentre os principais cordelistas gravadores podemos destacar a figura de José Francisco Borges, popularmente conhecido como J. Borges.

Assim, trabalhar com esse gênero literário poder tornar 0 conhecimento mais atrativo e contribuir para que a aprendizagem torne-se mais significativa e interdisciplinar,possibilitando aos alunos o sentimento de que são construtores de sua própria história. Segundo Alves (2008, p. 103), o trabalho com o cordel na escola desperta"o interesse do aluno pela condição social, histórica, política e econômica daqueles que produzem e lêem cordel", ou seja, pelas particularidades da cultura brasileira pela voz, especialmente, dos nordestinos. Essas contextualizações de conhecimento que se produz pelo uso da literatura de cordel permitem que se constitua um currículo que extrapole os "limites disciplinares", ou seja, uma possibilidade concreta de fazer um trabalho pedagógico norteado pelos princípios da interdisciplinaridade.

Portanto, pensando no cordel como metodologia para qualificar a escrita dos estudantes, mas, principalmente como manifestação artística e cultural que esse projeto foi elaborado. Desta forma, passamos no próximo segmento do texto a relatar como as atividades foram desenvolvidas de modo que a interdisciplinaridade norteasse nossas práticas pedagógicas, procurando superar a fragmentação curricular.

\section{Literatura em cordel: Leituras interdisciplinares}

Criar Educação, Criciúma, v. 6, n², julho/novembro 2017.- PPGE UNESC 
O conceito de interdisciplinaridade vem sendo bastante discutido atualmente no âmbito escolar, visto que a escola ainda apresenta um currículo fragmentado a partir de um sistema de ensino disciplinado, ou seja, separado por disciplinas. Sendo assim, percebe-se a necessidade de encontrar formas concretas de integração das diversas áreas do conhecimento, possibilitando diálogos entre os conteúdos com vistas a formação de um sujeito plural.

Segundo Fazenda (1979, p. 25) "a prática docente precisa superar e ultrapassar fronteiras disciplinares. Essa atitude se expressa, por exemplo, como habilidade para exercer trocas com outros professores (especialistas) e para integrar as disciplinas em projetos comuns".

Foi pensando nisso que procuramos elaborar um projeto que se propusesse a realizar um trabalho interdisciplinar que se efetivasse na prática, onde as disciplinas curriculares dialogassem a partir de um tema gerador e superassem a visão multidisciplinar. Trabalhar com projetos dividindo os conteúdos e ações entre as áreas é uma prática comum nas escolas, entretanto, trabalhar em prol da problematização e contextualização dos conhecimentos foi um desafio que assumimos enquanto professores em formação para a escola em que realizamos nosso projeto.

Entretanto, podemos destacar a partir das observações realizadas pelos bolsistas do PIBID que muitos professores permanecem estranhos uns aos outros na escola. Existem divisões de acordo com sua formação, de acordo com o nível de ensino em que atuam, falam linguagens diferentes, apresentam uma postura distante da união e do compartilhamento de saberes. É perceptível que ao tentar trazer a interdisciplinaridade para a sala de aula muitos apresentaram olhares desconfiados, pois implica sair de uma zona de conforto e assumir se aventurar por novos caminhos.

Segundo Japiassu (1976), a interdisciplinaridade exige uma reflexão profunda e inovadora sobre o conhecimento, que demonstra a insatisfação com o saber fragmentado. A prática docente deve refletir sobre a estrutura do conhecimento, para que consiga superar a forma de ensino utilizada pelo ensino tradicional.

Criar Educação, Criciúma, v. 6, n², julho/novembro 2017.- PPGE UNESC 
Além da aproximação e relação entre as disciplinas, a interdisciplinaridade está presente quando consegue integrar várias especialidades, utilizando também instrumentos de outras disciplinas, fazendoos integrarem, para em seguida, serem comparados e julgados.

\begin{abstract}
Podemos dizer que nos reconhecemos diante de um empreendimento interdisciplinar todas as vezes em que ele conseguir incorporar os resultados de várias especialidades, que tomar de empréstimo a outras disciplinas certos instrumentos e técnicas metodológicos, fazendo uso dos esquemas conceituais e das análises que se encontram nos diversos ramos do saber, a fim de fazê-los integrarem e convergirem, depois de terem sido comparados e julgados. Donde podermos dizer que o papel específico da atividade interdisciplinar consiste, primordialmente, em lançar uma ponte para ligar as fronteiras que haviam sido estabelecidas anteriormente entre as disciplinas com o objetivo preciso de assegurar a cada uma seu caráter propriamente positivo, segundo modos particulares e com resultados específicos (JAPIASSU, 1976, p. 75).
\end{abstract}

Assim, o projeto do "Cordão ao Cordel" tornou possível que o conhecimento fosse trabalhado interdisciplinarmente entre os componentes curriculares de Arte, História, Ensino Religioso e Língua Portuguesa. As ações foram desenvolvidas especificamente nas disciplinas citadas, visto que a escola ainda apresenta um currículo em formado de gavetas, um momento para cada área. Desta forma, procuramos nos adequar a essa situação sem prejudicar nosso objetivo maior, e no espaço oferecido criar interações entre as disciplinas. Nesse caminho, Pereira (2014, p. 114) contribui ao dizer que a interdisciplinaridade trata-se de "relação pedagógica, de forma deliberada e intencional, objetivando proporcionar ao aluno a construção e a produção de um conhecimento mais global, a partir das relações e intercomunicações que se fizeram necessárias à sua compreensão".

As primeiras ações do projeto procuraram interagir com os estudantes, valorizando os conhecimentos que eles traziam a respeito do assunto. Através de uma conversa sobre o tema, conteúdos interdisciplinares emergiram na discussão. Com a leitura de estrofes em cordel, os alunos foram instigados sobre o gênero literário e sobre sua história. A partir do filme "O auto da Compadecida" perceberam o sotaque nordestino, a seca, questões religiosas e sociais apresentadas pelos personagens. Desta forma, questões 
geográficas, sociais, culturais, artísticas, políticas, históricas se fizeram presentes nos debates que fluíram entre os bolsistas e a turma do $9^{\circ}$ ano no decorrer do projeto.

Nesse caminho, podemos destacar que a interdisciplinaridade buscou construir o conhecimento com base no contexto e história do indivíduo. O conceito de interdisciplinaridade vai além da articulação entre disciplinas, é questionar, refletir e ligar fronteiras. Segundo Pereira (2014, p. 87) ela "se compromete em problematizar suas limitações e possibilidades no que diz respeito à compreensão crítica do mundo".

Quando convidados a escreverem poemas em cordeis, as possibilidades se ampliaram ainda mais. Uma escrita que, a princípio parecia difícil para os estudantes, permitiu, a partir de um vocabulário popular e de seu cotidiano, expressarem sobre vivências particulares, percebendo-se também como produtores culturais.

A criação das capas foi outro momento importante para o projeto. A técnica utilizada foi da isogravura, visto que a xilogravura ao utilizar como suporte uma matriz em madeira, exige o uso de formões e goivas que, além de serem afiados, não teríamos a quantidade suficiente para todos os estudantes. Assim, os rabiscos criados na escola, foram gravados no papel na visita ao atelier de gravura da UNESC. Assim, o projeto foi estabelecendo um movimento de geral para o particular e do particular para o geral.

Não podemos deixar de destacar a importância desse momento para o processo de aprendizagem dos alunos. Sair da escola para visitar novos espaços é sempre uma oportunidade de ampliação dos conhecimentos e de vivências. Conhecer um atelier de gravura, conversar com a artista local AngêlicaNeumaier, conhecer suas obras, e ainda criarem as capas de seus cordéis nesse espaço, com a tinta apropriada e instrumentos especiais, foi um dos momentos mais destacados pelos alunos na avaliação final do projeto. Mostrou que o artista não é algo distante da realidade deles e que com as técnicas de gravura poderiam expressar o que sentiam, o que percebiam.

As conexões entre os saberes envolvidos pelo projeto aconteceram simultaneamente na medida em que as disciplinas, embora em momentos e

Criar Educação, Criciúma, v. 6, n², julho/novembro 2017.- PPGE UNESC 
áreas diferentes, iam tratando sobre $\mathrm{o}$ assunto $\mathrm{e}$ através das ações desenvolvidas pelos bolsistas do PIBID. Assim sendo, podemos afirmar que a interdisciplinaridade foi 0 elo integrador entre as áreas para tornar 0 conhecimento mais significativo e atraente para os alunos, pois, segundo Zabala (2002), a interdisciplinaridade acontece desde o simples diálogo entre as ideias até a integração das teorias, conhecimentos e pesquisa de duas ou mais disciplinas.

Por fim, a finalização do projeto deu-se por meio de um momento de trocas de saberes e sabores, e registros. As produções dos alunos foram socializadas, ouviram músicas que caracterizam o nordeste brasileiro e provaram a tapioca. A exposição dos trabalhos permaneceu por duas semanas na escola.

Podemos destacar, por fim, que a elaboração de poemas em cordel teve um grande valor para a construção do conhecimento, tanto como metodologia de ensino, como reconhecedor das manifestações da cultura popular, não nos esquecendo, porém, da importância da interdisciplinaridade para que esse projeto se concretizasse na realidade escolar. Pois, segundoThiesen (2008, p. 545) a interdisciplinaridade "busca responder à necessidade de superação da visão fragmentada nos processos de produção e socialização do conhecimento", sendo assim, esse projeto, foi um forte disseminador do conhecimento a partir de uma abordagem interdisciplinar.

\section{Considerações Finais}

Os resultados obtidos através da experiência do cordel corroboram com a afirmação de Fazenda (1994), ao dizer que a interdisciplinaridade possui a capacidade de expandir os horizontes da sala de aula. De fato, a importância da interdisciplinaridade foi comprovada com a realização desse projeto, onde observou-se avanços no desenvolvimento da turma a partir da participação nas aulas e da superação das dificuldades encontradas em seu início. As leituras e discussões proporcionaram um olhar crítico sobre o tema, assimilando de

Criar Educação, Criciúma, v. 6, n², julho/novembro 2017.- PPGE - 
forma ampla e significativa o conhecimento. A valorização da criação, reescrita e contextualização dos poemas em cordel tambémfortaleceram a segurança no ato de escrever.

Podemos destacar que o exercício da prática docente exige do profissional um conhecimento amplo da realidade, que vá além de sua área de formação para promover um avanço de todo o processo de ensinoaprendizagem. Assim, encontramos na interdisciplinaridade uma possibilidade de integração desses conhecimentos, superando a fragmentação, pois na escola os conhecimentos comungam de um mesmo espaço. Nesses moldes, o professor terá que sair de seu campo disciplinar, sua zona de conforto, e interagir com outras áreas, dando espaço a um conhecimento mais amplo, o que permitirá aos alunos relacioná-las, questioná-las.

Nesse caminho o projeto desenvolvido com os alunos de $9^{\circ}$ ano de uma escola da rede pública contribuiu significativamente em vários fatores. Podemos destacar a ampliação do repertório artístico-cultural, o conhecimento das particularidades das regiões do Brasil, da cultura brasileira como um todo, o exercício da escrita, a valorização do conhecimento e experiência do aluno, vivências estéticas por meio de leituras de poemas, produções e leituras de imagens, dentre outros. Podemos destacar, também, a contribuição do mesmo para a formação complementar dos professores da escola e bolsistas do projeto subprojeto interdisciplinar do PIBID. Pois, o envolvimento sério de cada integrante exigiu pesquisas sobre como integrar sua disciplina superando a fragmentação curricular, fortalecendo a formação docente, transformando-se também em uma ferramenta de complementação pedagógica para o professor.

\section{Referências}

ALVES, R. M. Literatura de cordel: por que e para que trabalhar em sala de aula. Revista Fórum Identidades. Ano 2. Volume 4, jul/dez de 2008, p.103109.

Criar Educação, Criciúma, v. 6, n², julho/novembro 2017.- PPGE UNESC 


\section{CRIAR EDUCAÇÃO \\ Revista do Programa de Pós-Graduação em Educação - UNESC}

ATEU, A.DocumentÁrio:A Sina de PATATIVA do AsSARÉ. JoRnAl GGN, maio, 2012. Blog Antonio Ateu. Disponível em:

<HTTP://JORNALGGN.COM.BR/BLOG/ANTONIO-ATEU/DOCUMENTARIOA-SINA-DEPATATIVA-DO-ASSARE>. ACESSO EM: 16MAIO 2016.

FAZENDA, I. C. A. (Org.). Integração e interdisciplinaridade no ensino brasileiro: efetividade ou ideologia? São Paulo: Loyola, 1979.

FAZENDA, I. C. Interdisciplinaridade: História, teoria e pesquisa. 13.ed. Capinas: Papirus Editora. 1994.

FREIRE, P. Pedagogia da autonomia: saberes necessários à prática educativa. 43.ed. Rio de Janeiro: Paz e Terra, 2011.

GANDIN, D. Planejamento como prática educativa. 11 ed. São Paulo: Ed. Loyola, 2000.

JAPIASSU, H. Interdisciplinaridade e patologia do saber. Rio de Janeiro: Imago, 1976.

LESSA, O. Getúlio Vargas na literatura de cordel. Rio de Janeiro: Documentário, 1973.

MAXADO, F. Cordel:xilogravura \& ilustrações. Rio de Janeiro: Codecri. 1982.

PEREIRA, A. S. E por falar em educação... ensino, formação e gestão. Criciúma, SC: UNESC, 2014.

PROENÇA, I. C. A ideologia do Cordel. Rio de Janeiro: Imago. 1976.

THIESEN, J. DA S. A interdisciplinaridade como um movimento articulador no processo ensino-aprendizagem. Rev. Bras. Educ. [online]. 2008, vol.13, n.39, p. 545-554.

VASCONCELLOS, C. DOS S. Construção do conhecimento: em sala de aula. 10. ed. São Paulo: Libertad, 2000.

ZABALA, A. Enfoque globalizador e pensamento complexo: uma proposta para o currículo escolar. Porto Alegre: Editora Artmed, 2002.

Criar Educação, Criciúma, v. 6, n², julho/novembro 2017.- PPGE UNESC 